\title{
Applications of Nanocarriers as Drug Delivery Vehicles for Active Phytoconstituents
}

\author{
Phui $_{3}$ Qi Ng ${ }^{1}$, Laura Soon Cheau Ling ${ }^{1}$, Jestin Chellian ${ }_{5}^{2}$, Thiagarajan Madheswaran ${ }^{3}$, Jithendra Panneersel-

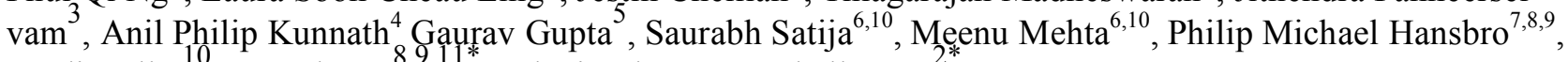 \\ Trudi Collet ${ }^{10}$, Kamal Dua ${ }^{8,9,1^{*}}$ and Dinesh Kumar Chellappan ${ }^{*}$
}

\begin{abstract}
${ }^{1}$ School of Pharmacy, International Medical University (IMU), Bukit Jalil, Kuala Lumpur, 57000, Malaysia; ${ }^{2}$ Department of Life Sciences, School of Pharmacy, International Medical University (IMU), Bukit Jalil, Kuala Lumpur, 57000, Malaysia; ${ }^{3}$ Department of Pharmaceutical Technology, School of Pharmacy, International Medical University (IMU), Bukit Jalil, Kuala Lumpur, 57000, Malaysia; ${ }^{4}$ Division of Applied Biomedical Science and Biotechnology, School of Health Sciences, International Medical University, Bukit Jalil, Kuala Lumpur, Malaysia 57000; ${ }^{5}$ School of Pharmacy, Suresh Gyan Vihar University, Jagatpura, Jaipur, 302017, India; ${ }^{6}$ School of Pharmaceutical Sciences, Lovely Professional University, Phagwara, Punjab, India 144411; ${ }^{7}$ School of Life Sciences, Faculty of Science, University of Technology Sydney, Ultimo, NSW 2007, Australia; ${ }^{8}$ Priority Research Centre for Healthy Lungs, Hunter Medical Research Institute (HMRI) \& School of Biomedical Sciences and Pharmacy, The University of Newcastle (UoN), Callaghan, NSW 2308, Australia; ${ }^{9}$ Centre for Inflammation, Centenary Institute, Sydney, NSW 2050, Australia; ${ }^{10}$ Innovative Medicines Group, Institute of Health and Biomedical Innovation, Queensland University of Technology (QUT), Kelvin Grove, Brisbane, Queensland 4059, Australia; ${ }^{11}$ Discipline of Pharmacy, Graduate School of Health, University of Technology Sydney, Ultimo, NSW 2007, Australia

A R T I C L E H I S T O R Y
Received: February 25,2020
Accepted: April 17, 2020
DOI:
10.2174/1381612826666200610111013

$10.2174 / 1381612826666200610111013$

Abstract: Many plant-based bioactive compounds have been serving as the origin of drugs since long ago and many of them have been proven to have medicinal value against various chronic diseases, including, cancer, arthritis, hepatic diseases, type- 2 diabetes and cardiovascular diseases. However, their clinical applications have
been limited due to their poor water solubility, stability, low bioavailability and extensive transformation due to been limited due to their poor water solubility, stability, low bioavailability and extensive transformation due to the first-pass metabolism. The applications of nanocarriers have been proven to be able to improve the delivery of bioactive phytoconstituents, resulting in the enhancement of various pharmacokinetic properties and thereby increasing the therapeutic value of phytoconstituents. These biocompatible nanocarriers also exert low toxicity to
healthy cells. This review focuses on the uses and applications of different types of nanocarriers to enhance the increasing the therapeutic value of phytoconstituents. These biocompatible nanocarriers also exert low toxicity to
healthy cells. This review focuses on the uses and applications of different types of nanocarriers to enhance the delivery of phytoconstituents for the treatment of various chronic diseases, along with comparisons related to bioavailability and therapeutic efficacy of nano phytoconstituents with native phytoconstituents.
\end{abstract}

Keywords: Phytoconstituents, nanocarriers, bioavailability, chronic diseases, nanoparticles, nanomedicine.

\section{INTRODUCTION}

Plants have, from time immemorial, remained as a diverse source for the discovery of various forms of therapeutic agents [1]. Plant-derived medicine is believed to be a safer alternative to conventional medicine without compromising its effectiveness in treatment [2-4]. Some plants have a protective effect on human cells, which can minimise the damage caused by the treatment [57]. However, plant-derived medicine faces challenges in terms of drug delivery and targeted effects with a reduced availability at the desired site. This may be attributed to its poor stability and solubility, along with the rapid elimination from the body systems [8-10]. This demands an immediate need for an efficient delivery system to deliver the active constituents specifically to the desired site of action in a sustained manner while keeping the toxicity effects at its minimum [11,12].

The rise of pharmaceutical technology has led to the development of nanocarriers as the principal drug transport agents. Nanocarriers are drug transport modules with submicron particle size, generally below $500 \mathrm{~nm}[13,14]$. Owing to their small size, they have the ability to improve the properties of the drug and carry the

*Address correspondence to these authors at the Department of Life Sciences, School of Pharmacy, International Medical University (IMU), Bukit Jalil, Kuala Lumpur, 57000, Malaysia;

E-mail Dinesh_Kumar@imu.edu.my; kamal.dua@uts.edu.au drug to the specific target site. It has been established that the nanoparticle drug carriers are able to accumulate specifically at target sites owing to their passive targeting mechanisms, by continuously supplying the encapsulated agent to the site [15]. Thus, nanocarriers are able to improve the properties and effects of plantderived medicine, producing a safer and more effective treatment option, with the combination of natural products and nanotechnology [16].

Different nanocarriers are employed based on their properties and the mode of treatment involved. Common nanomaterials include liposomes, solid lipid nanoparticles and metal nanoparticles, such as gold and silver nanoparticles [17]. Liposomes are spherical vesicles consisting of at least one phase of the lipid layer and spontaneously assemble into bilayers once in contact with water. Hence, liposomal systems can be employed to encapsulate drugs made of both lipophilic and hydrophilic compounds, making them the ideal carrier for a diverse range of drugs [18-20]. Metal nanoparticles, such as gold and silver nanoparticles, are often used in the management of wounds, due to their known anti-microbial and antiinflammatory effects [21]. Silver exerts an anti-bacterial effect by attaching thiol groups to enzymes, which are also required for respiratory chains of bacteria $[22,23]$. Silver nanoparticles take advantage of the high-surface-to-volume ratio of nanoparticles to increase the contact area to the bacteria, resulting in a higher amount of silver ions to perform its bactericidal activities [24]. In addition to 


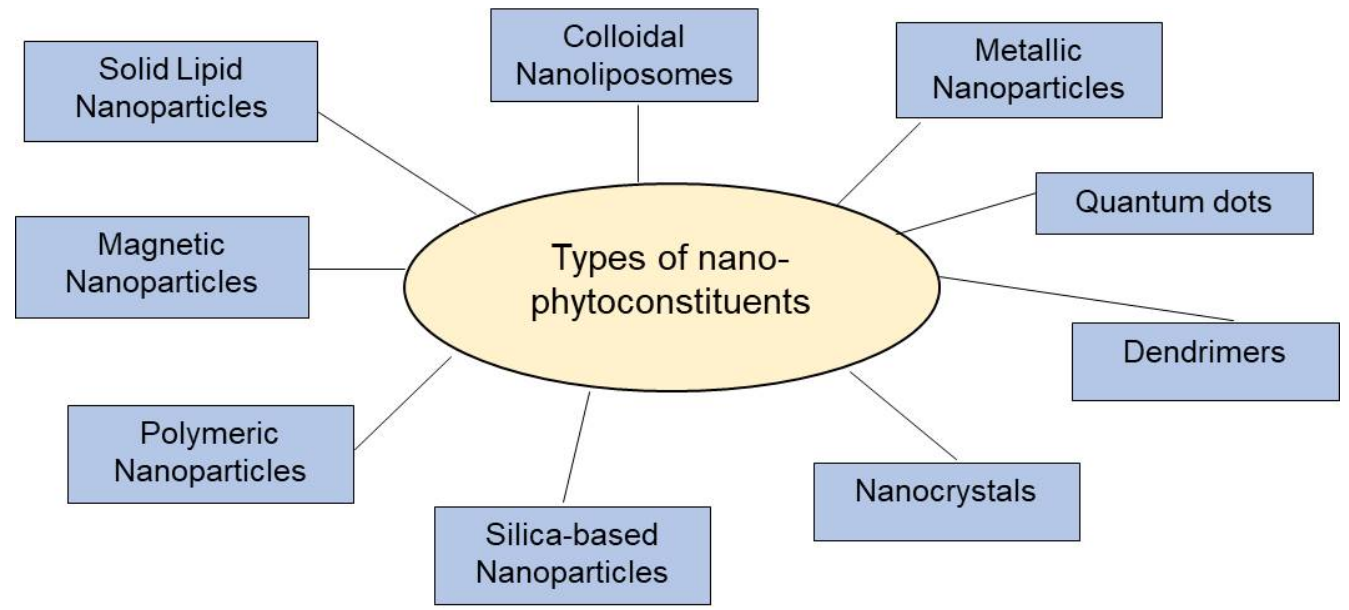

Fig. (1). Types of nanocarriers for the delivery of therapeutic phytoconstituents. (A higher resolution / colour version of this figure is available in the electronic copy of the article).

that, solid lipid nanoparticles are another type of colloidal nanosized delivery system which is made up of surfactant-stabilised lipids that remain in a solid-state at room and body temperature. They are generally stable and are capable of targeted delivery and carry lipophilic and hydrophilic drugs [25,26]. Furthermore, niosomes are vesicles made of non-ionic surfactant with cholesterol incorporated as an excipient. They have a high penetrating ability and are stable to be used in body systems [27-29]. Those mentioned earlier are some of the common nanocarriers, but other types of nanocarriers also will be discussed in this review, along with their applications and therapeutic uses.

\section{ADVANTAGES OF NANOCARRIERS}

Different natural phytoconstituents have comprehensive biological activities and broad therapeutic efficacies in chronic diseases. The biggest advantage of using phytoconstituents is that they treat adverse effects significantly and effectively as compared to any other dosage forms. The physiochemical properties such as low solubility, low permeation and non-objective efficacy at the active site are the common barriers to their therapeutic effectiveness. Different nanocarrier based approaches are used to resolve these obstacles, thereby, providing a sustained and consistent therapeutic targeting at required concentrations to enhance the therapeutic effectiveness at the active site $[9,10,30-32]$.

The use of nanocarriers (Figure 1) for plant-derived medicines has provided a huge benefit by enhancing their bioavailability and selectivity towards the target site, resulting in a more effective and less harmful treatment outcome [33]. Nanocarriers can be designed to release drugs in a controlled manner from their reservoirs. This will maintain a constant amount of drug in the targeted site and, subsequently, reduce the frequency of drug administration required [34]. Not only do nanocarriers achieve a more effective, selective and safer therapeutic effect, but they also offer a more convenient and better compliance when it comes to treatment options, to majority of the patients [35].

\section{LIMITATIONS OF NANOCARRIERS}

Comprehensive knowledge of health and toxicological issues is important to exploit the potential and usability of nanocarriers. Furthermore, this becomes essential to overcome the limitations of the nanocarrier being used. The so-called therapeutic ratio or index, which lies between the dose required for clinical effectiveness and the dose-inducing side effects (toxicity), can be largely improved by employing different drug delivery formulations for pharmaceutical products. Nevertheless, toxicological analysis is also required for these particular formulations [36].
In contrast with bulk materials, nanocarriers are developed for their unique (surface) properties. As nanocarriers come in contact with bodily tissues and surfaces when administered, a toxicological profile of the nanocarrier employed is required. Nanocarriers could possess toxic properties. It may be possible to identify certain risks associated with the use of these nanoparticles using current tests and procedures [37].

There are various other factors which should be taken into account with the use of nanocarriers. One of which is the stability of nanoparticles [38]. Nanoparticles tend to aggregate at low drug concentrations and the drug entrapment may vary due to polydispersity [39]. This will ultimately affect their efficiency and solubility in body systems. Another concern is the long-term risk of toxicity with the use of nanocarriers. Nanoparticles have been said to affect certain physiological systems because they generate reactive oxygen species, which might lead to increased oxidative stress and induce inflammation [40,41]. However, toxicity data on the use of nanoparticles are conflicting [42]. Thus, more studies are needed to establish the toxicity of nanoparticles, to further understand their mechanisms and develop solutions to reduce such toxicity risks.

The various therapeutic applications exhibited by nanoparticles as a drug delivery containing phytoconstituents are discussed below;

\subsection{Anticancer}

Numerous plant-derived active constituents, like, boswellic acid, curcumin, vinca species, Tagetes erecta species and many others have been used to prevent and stop the proliferation of cancerous cells [7, 33,43-46]. Many studies have demonstrated that the active compounds present in the plants are able to show anticancer activity [47]. Curcumin, the polyphenol extracted from the plant Curcuma longa [48] was able to inhibit the proliferation and angiogenesis of cancer cells and inducing apoptosis $[32,49,50]$. Studies have demonstrated that curcumin hindered the growth of cancer cells via modulation of different molecular pathways [51], such as activation of tumor suppressor gene (p53 and PTEN), inactivation of vascular endothelial growth factors (VEGF), namely, Akt and phosphoinositide-3-kinase (PI3K), and also by suppressing the production of nuclear factor- $\mathrm{\kappa B}(\mathrm{NF}-\mathrm{\kappa B})$ regulated gene product (Fig. 2) [49,52].

The main drawback is that curcumin has poor solubility and bioavailability. Hence poly(lactic-co-glycolic acid) (PLGA) nanoparticles loaded with curcumin were developed to enhance its clinical uses. These nano curcumin particles have been tested on CaSki and SiHa cervical cancer cells and the results showed that the nanocurcumin could inhibit cell growth and induce apoptosis more 


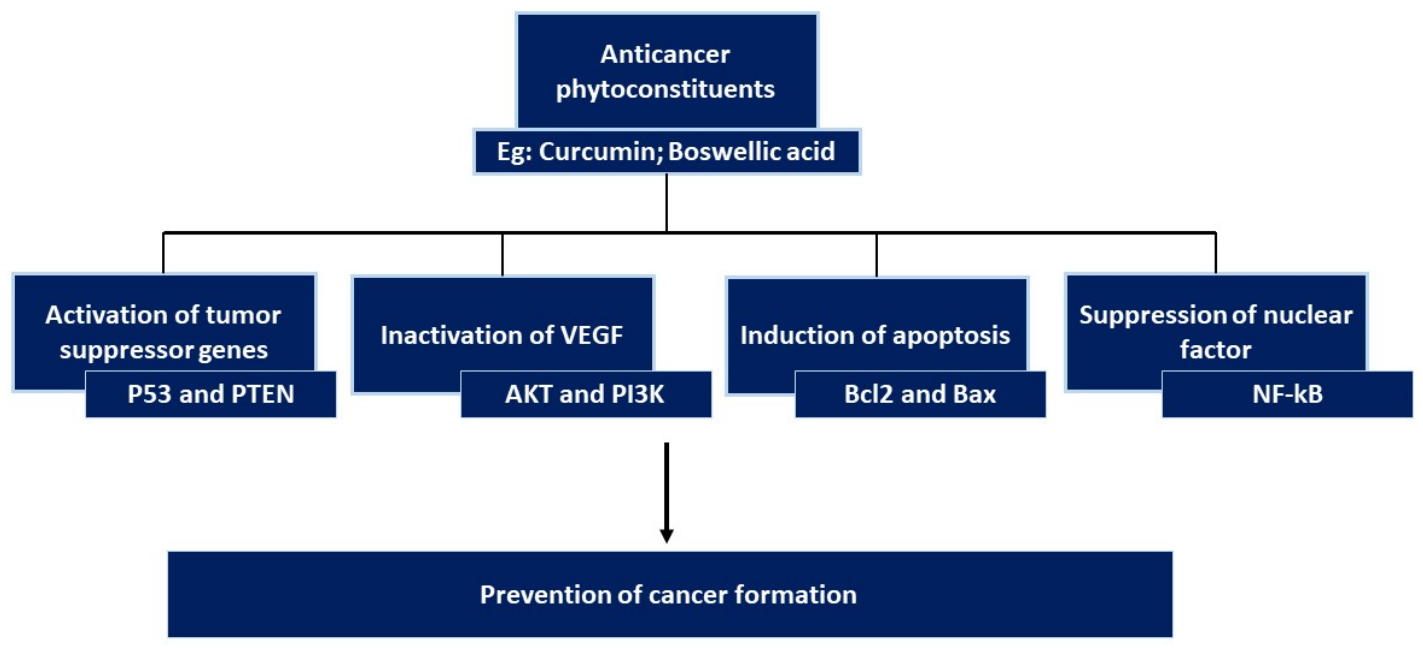

Fig. (2). Role of anticancer phytoconstituents like curcumin and boswellic acid in the prevention of cancer through the inhibition of initiation, promotion, and progression via modulation of molecular cascades. (A higher resolution / colour version of this figure is available in the electronic copy of the article).

effectively compared to free curcumin. The miRNA-21, nuclear $\beta$ catenin and E6/E7 HPV oncoproteins were found to be effectively reduced in the orthotopic mouse model treated with nanocurcumin [53]. The same PLGA nanocurcumin synthesized with poly(Llysine) and poly(vinyl alcohol) stabilizer by using nanoprecipitation method has been reported to have higher cellular uptake and better cell proliferation suppression for both cisplatin-resistant ovarian cancer cells and metastatic breast cancer compared to free curcumin [54]. Ndong et al., produced cyclodextrin/cellulose nanocrystal complexes using curcumin with improved antiproliferative action against human prostatic and colorectal cell lines [55]. Similarly, the curcumin-loaded polymer-coated magnetic nanoparticles were reported to be able to reduce the survival of malignant human ovarian carcinoma cells [56].

Noscapine, an alkaloid extracted from the Opium poppy, Papaver somniferum [1] was found to have antimitotic activity. This active phytoconstituent was later on tested on a mouse model, where it demonstrated anticancer activity in vivo against cancerous cell proliferation. Noscapine targets and interferes with microtubule formation, arrests mitosis, suppresses tumour growth and eventually promotes cancerous cell death [57]. Noscapine has limited clinical progression due to its hydrophilicity. It has a high elimination rate with short plasma half-life when administered intravenously, whereas oral administration requires a highly effective dose. Hence, the development of alternative formulations is necessary to improve the bioavailability of noscapine. Madan and colleagues constructed and customised noscapine solid lipid nanoparticles (SLN) conjugated with poly (ethylene)-glycol. This formulation showed a higher glioblastoma cell uptake and higher cytotoxicity with a lower inhibitory concentration required, in comparison with pure noscapine. The plasma half-life of noscapine PEG solid-lipid nanoparticles was 11 -fold higher with a longer retention time of noscapine nanoparticles in mice brain. This probably would have been contributed by a lower volume of distribution and a lower rate of clearance of nanoparticles [58]. However, brominated derivatives of noscapine were found to have greater tubulin binding activity than noscapine [59]. Jyoti et al., developed nanostructured lipid particles loaded with noscapine analogue, 9-bromo-noscapine by nanoemulsion method to minimize the particles' size down to $100 \mathrm{~nm}$. This inhalable formulation exhibited improved cellular uptake, cancerous cell killing and apoptosis in lung cancer cell lines, as well as, a longer plasma half-life than 9-bromo noscapine nanoparticles and 9-bromo noscapine suspension [60].

Phytoconstituents like berberine, which could be derived from Coptidis rhizome, have also demonstrated suppressive effects on the growth of cancerous cells [61-64]. However, the poor water solubility of berberine makes it less effective and difficult for uptake by the body. Thus novel delivery systems have been employed lately to enhance the bioavailability of berberine. For example, silver nanoparticles (AgNPs) were synthesized by Bhanumathi et al., using Syzygium cumini seed extract for the productive incorporation of berberine. The inhibitory concentration for half of the cell death, IC50 for berberine loaded AgNPs was lower than both the biogenic NPs and free berberine in MDA-MB-231 breast cancer cells. This novel biogenic AgNPs released berberine into breast cancer cells selectively and hence drug loss in the blood circulation was minimized [65]. Wang et al., developed SLN for the encapsulation of berberine with particle size $82 \mathrm{~nm}$. Berberine loaded SLNs showed slower drug release and higher antitumor efficacy on MCF7 breast cancer cells when compared to free berberine [66]. Berberine that is conjugated and encapsulated with dendrimers was developed and both the formulations showed excellent anti-tumour potential. Gupta et al., then compared the pharmacokinetic profile of encapsulated and conjugated formulations in the delivery of berberine using dendrimers. Results revealed that the conjugated formulation showed better pharmacokinetics, higher drug load and longer circulation half-life compared to the encapsulated formulation [67]. Recently, Li et al., developed a nanocarrier for incorporating berberine and miR-122 using polyethyleneimine-cholesterol (PC) with a particle size of $192 \mathrm{~nm}$. PC loaded with berberine and miR-122 could inhibit in vitro cancer cell invasion effectively and hence suggested that PC is a better preferred nanocarrier for intracellular delivery of berberine in treating cancer [68].

On the whole, these biologically degradable nanocarriers have unique structural and physical properties that are highly important in the targeted delivery of anti-cancer and image contrast agents. These intelligent carriers are designed to act on malignant cells, while, keeping healthy cells discreet. The above mentioned studies largely provide the current status of nanocarriers that are built as target-supply systems for anticancer drugs which are currently in clinical use. A list of nanocarriers and the type of delivery system currently used for the delivery of anticancer phytoconstituents is shown in Table $\mathbf{1}$.

\subsection{Anti-Arthritic}

Quercetin, resveratrol and curcumin are some of the plant-based bioactive compounds that have been studied for their anti-arthritic potential. These phytoconstituents could relieve pain and swelling in rheumatoid arthritis by inhibiting inflammation-causing mediators in the body [70]. Quercetin has shown to be capable of improv- 
Table 1. Nanocarriers for anticancer phytoconstituents.

\begin{tabular}{|c|c|c|c|c|}
\hline $\begin{array}{l}\text { Bioactive } \\
\text { compound }\end{array}$ & Nanocarrier & Type of delivery system & Experimental model & References \\
\hline \multirow[t]{4}{*}{ Curcumin } & \multirow[t]{2}{*}{ Nanoparticles } & PLGA based curcumin nanoparticles & In-vitro/In-vivo (rats) & {$[53]$} \\
\hline & & $\begin{array}{l}\text { PLGA based curcumin nanoparticles with poly(vinyl alcohol) and } \\
\text { poly(L-lysine) stabilizers }\end{array}$ & In-vitro & {$[54]$} \\
\hline & Nanocrystal & Curcumin cyclodextrin/cellulose nanocrystal complexes & In-vitro & {$[55]$} \\
\hline & Magnetic nanoparticles & Polymer-coated magnetic nanoparticles & In-vitro & [69] \\
\hline \multirow[t]{2}{*}{ Noscapine } & Nanoparticles & Solid-lipid nanoparticles conjugated with poly(ethylene)-glycol & In-vitro & {$[58]$} \\
\hline & $\begin{array}{l}\text { Lipid-based } \\
\text { nanoparticles }\end{array}$ & Nanostructured lipid nanoparticles loaded with noscapine & In-vitro/In-vivo & {$[61]$} \\
\hline \multirow[t]{4}{*}{ Berberine } & \multirow[t]{3}{*}{ Nanoparticles } & Silver nanoparticles & In-vitro/In-vivo & {$[65]$} \\
\hline & & Solid lipid nanoparticles & In-vitro/In-vivo & {$[66]$} \\
\hline & & Dendrimer-encapsulated and conjugated nanoparticles & In-vitro/In-vivo & [67] \\
\hline & Polymeric nanoparticle & Polyethyleneimine-cholesterol loaded with berberine and $m i \mathrm{R}-122$ & In-vitro & {$[68]$} \\
\hline
\end{tabular}

ing arthritic conditions in animal studies. It prevents inflammatory responses by blocking the inflammatory transcription factors from being generated and released into the synovial joint [71,72]. Furthermore, this semi-lipophilic compound, quercetin, has been encapsulated into various nanosized vectors to improve its bioavailability. Jeyadevi et al., developed a nanoformulation containing quercetin of $185 \mathrm{~nm}$ size, composed of thioglycolic acid capped cadmium, quantum dots and quercetin. Quantum dots were used due to their unique features that could improve the target delivery of the drug. These nanoparticles reduced C-reactive protein and a rheumatoid factor, which were otherwise elevated in Wistar rats with arthritis in a dose-dependent manner. Thus, this study concluded that employing quantum dots as nanocarriers could enhance the anti-arthritic effect of quercetin, as a minimal concentration of formulation was sufficient enough to prevent cartilage destruction in the rats [73].

Capsaicin, a potent biomolecule, which could be extracted from chili pepper, was reported to reduce the pain of arthritis by acting deeper on the skin tissue. In order to enhance skin penetration of capsaicin, this lipophilic compound was encapsulated into a lipid vesicular system, transfersomes by Sawar et al., who evaluated their topical anti-arthritic potential in an experimental rat model. The capsaicin-loaded transfersomes were synthesized using tween 80 and phosphatidylcholine, with a particle size of $94 \mathrm{~nm}$. The transfersomes delivery system showed better skin penetration and a required concentration of the drug could be delivered effectively to the target site for treating inflammatory arthritis [74]. Furthermore, the same researchers used ethosomes as nanocarriers to incorporate capsaicin. This ethosomal delivery system exhibited pronounced stability with no structural changes detected after up to one year of storage at room temperature. Significant reduction of inflammation, better skin penetration along with low skin irritation were observed in topical ethosomal capsaicin-treated rats with arthritis [75].

Another potential biomolecule, piperine, exerted its antirheumatic activity through the inhibition of prostaglandin production [76]. Piperine-loaded solid lipid nanoparticles, which were synthesized by melt emulsification techniques were studied for their potential to treat rheumatoid arthritis. These SLNs with an average size of $128 \mathrm{~nm}$ and entrapment efficiency of $78.71 \%$ were administered into CFA-induced arthritic rats through oral and intravenous routes. Results showed that the formulation reduces tumor necrosis factor and TNF- $\alpha$ significantly compared to chloroquine suspension, which was the standard substance in the experiment [77]. Hesperidin is another plant-based compound that has a potential anti-rheumatic effect. Bhalekar et al., reported better diseasemodifying action of hesperidin when formulated in solid lipid nanoparticles. This study also demonstrated that both oral and topical SLN formulations loaded with hesperidin did not show significant differences in in-vitro drug release, radiological analysis, histopathological study and tumor necrosis factor-alpha analysis [78]. In a recent study, hesperidin-loaded silver nanoparticles that were stabilized using acacia gum showed better control in tissue swelling of the joints and lesser joint degeneration compared to free hesperidin [79].

Curcumin, another potent biomolecule, was also able to show the therapeutic effect on arthritis by lowering the production of inflammatory mediators including, TNF- $\alpha$, interleukin-1, nuclear factor-kappa and hypoxia-inducible factor-1 $\alpha$ [80]. An oil in water nanoemulsion was formulated by Zheng et al., using a highpressure homogenizing method to improve the oral bioavailability of hydrophobic curcumin. This nanoemulsion with an average diameter of $150 \mathrm{~nm}$ exhibited better antiarthritic activity in adjuvantinduced arthritis in rats compared to oral curcumin suspension. The formulation showed a threefold higher area under the curve (AUC) value and $\mathrm{C}_{\max }$ in bioavailability studies. The values for inhibition of two major cytokines, IL- $1 \beta$, and TNF- $\alpha$, for both oral curcumin nanoemulsion and intravenous curcumin solution were similar. However, the oral nanoemulsion showed slightly better anticytokine value compared to the standard methotrexate injection. Hence, this study concluded that curcumin nanoemulsion could be an effective antirheumatic agent that could be delivered via oral administration [81]. Furthermore, Zhang and his colleagues formulated a patient-friendly topical application of curcumin-loaded polymeric nanoparticles. Their study was carried out as an in-vivo study. In this study, topical curcumin nanoparticles showed a potent effect on cartilage homeostasis. The post-traumatic osteoarthritic mouse treated with curcumin nanoparticles not only demonstrated lesser pathological changes of cartilage but also, experienced lesser pain associated with osteoarthritis [82]. Niazvand et al., developed oral curcumin nanoparticles, which were conjugated with PLGA 
Table 2. Nanocarriers for anti-arthritic phytoconstituents.

\begin{tabular}{|c|c|c|c|c|}
\hline $\begin{array}{c}\text { Bioactive } \\
\text { compound }\end{array}$ & Nanocarrier & Type of delivery system & Experimental model & References \\
\hline \hline Quercetin & Quantum dot nanoparticles & Glycolic-acid capped cadmium telluride quantum dots & In-vitro/In-vivo & {$[73]$} \\
\hline Capsaicin & Lipid-based nanoparticles & Capsaicin-loaded transfersomes & In-vivo & In-vivo \\
\cline { 2 - 5 } & & Ethosomal capsaicin & In-vivo \\
\hline Piperine & Solid lipid nanoparticle & Piperine-loaded solid lipid nanoparticle & {$[77]$} \\
\hline Hesperidin & Solid lipid nanoparticle & Hesperidin-loaded solid lipid nanoparticle & In-vitro/In-vivo & [78] \\
\cline { 2 - 5 } & Silver nanoparticle & Hesperidin-loaded in gum acacia & In-vivo \\
\hline Curcumin & Nanoemulsion & Oil-in-water nanoemulsion containing curcumin in oil phase & In-vivo \\
\cline { 2 - 5 } & Polymeric nanoparticle & Polymeric nanoparticle loaded with curcumin & In-vitro/In-vivo & {$[81]$} \\
\hline & Nanoparticle & Curcumin-loaded PLGA nanoparticles & In-vivo \\
\hline
\end{tabular}

and evaluated their effect on monoiodoacetate-induced osteoarthritis rats. These topically administered nanoparticles improved the matrix staining of the articular cartilage and believed nanoparticles might be able to penetrate into cartilage and restore matrix synthesis. Overall, curcumin nanoparticles showed an enhanced chondroprotective effect compared to free curcumin [83].

Nanocarriers have evolved rapidly, as the need for advanced therapies in inflammatory disorders emerged. These nanocarriers deliver a wide variety of nanomaterials and resources, that can diagnose and treat various inflammatory conditions. The studies discussed above focus on the present and future applications of nanocarriers to positively treat inflammatory conditions such as arthritis, asthma and systemic inflammation, to name a few. It is imperative to use nanotechnology and nanocarriers, that may continue to stay as a formidable platform to solve most of the problems associated with the current conventional delivery methods, e.g., increased drug penetration into active microbial infection sites while reducing their side effects through drug carriers. The nanocarriers and the type of delivery system currently employed for the targeted delivery of anti-arthritic phytoconstituents are summarised in Table 2.

\subsection{Antidiabetic Effect}

There are several nanocarriers that are currently used for the targeted delivery of antidiabetic phytoconstituents (Table 3). Various investigations have shown that ingestion of phytobioactivecompound-rich foods such as polyphenols, curcumin and flavanones could treat type 2 diabetes mellitus. Nevertheless, many food grade phytoconstituents have low solubility in water. Thus, several nano delivery systems are employed to improve the bioavailability and therapeutic effect of such plant-based antidiabetic compounds $[4,84-86]$. Berberine has been found to have a pronounced effect in reducing blood glucose level in type 2 diabetes mellitus (T2DM). It improves the glucose sensitivity of the patients by activating the insulin signaling pathway and AMP kinasemediated pathway [87]. Berberine has been loaded in several novel nano delivery systems to improve the bioavailability of berberine. For example, berberine-loaded solid lipid nanoparticles with an average particle size of $76.8 \mathrm{~nm}$ were prepared by Xue et al., who evaluated their hypoglycemic effect in-vivo. SLN delivery system enhances the hypoglycemic effect of berberine by entrapping berberine in the nanocarrier and further improves its bioavailability in plasma. The berberine-loaded SLNs exhibited a stronger antidiabetic effect compared with free berberine at an equivalent dose. In addition, they showed a significant suppressive effect on increased body weight and fasting high blood glucose levels in diabetic mice [88]. The same researchers then found that liver is the dominant tissue for berberine distribution. Drug concentrations of berberineloaded SLNs in the liver were significantly higher than free berberine. Thereby, nanoparticles accumulated in the liver were able to enhance lipolysis in diabetic mice [89]. In another study, a berberine-loaded nanosuspension was prepared with a particle size of $72.4 \mathrm{~nm}$. The formulation was studied for its oral hypoglycemic potential in streptozotocin-induced diabetic mice. These nanosuspensions were synthesized using high-pressure homogenization method to produce small desired particle size, less than 200 $\mathrm{nm}$ to prolong drug circulation in blood. A higher bioavailability and drug plasma concentrations were observed in berberine-loaded nanosuspension. Thus, a lower dose of the nanosuspension was able to decrease blood glucose level and increase lipid metabolism in diabetic mice. Recently, selenium-coated nanostructured lipid carrier (NLC) delivery system with an average particle size of $160 \mathrm{~nm}$ was developed with berberine using hot-melt dispersion/homogenization procedure [90]. NLC, a new generation of solid lipid delivery system possessed lower particle size, greater stability and higher drug loading over solid lipid nanoparticles. However, this lipid-based formulation was unable to resist themselves from undergoing lipolysis in the harsh environment of the gastrointestinal tract [91]. Hence, Yin et al., coated the NLCs with selenium to reinforce their stability in the gastrointestinal tract. The selenium-coated NLCs demonstrated an enhanced oral bioavailability and hypoglycemic effect which was about six-fold greater than berberine solution. Results also revealed that selenium-coated NLCs with sustained release properties could be easily taken up by the cells which stimulated glucose utilization by adipocytes [92]

Baicalin is a hydrophobic phytoconstituent which can be extracted from Scutellaria baicalensis. It has a potential therapeutic effect against T2DM. Multiple novel delivery systems have been developed to increase the solubility and oral bioavailability of baicalin [93]. A nano delivery system was formulated by using water, oil, surfactant and co-surfactant to produce nanoemulsions loaded with baicalin. The nanoemulsions prepared by internal and external addition of baicalin were compared. The findings revealed that there were no significant differences between the two formulations in terms of particle size, drug content, polydispersity index and invitro release behavior. However, nanoemulsions with the internal addition of baicalin showed a higher AUC $(0-\infty)$ value than the nanoemulsion with external baicalin addition and free baicalin. The findings suggested that baicalin might be useful for treating various 
disease conditions, including T2DM [94]. In another study, Shi et al., developed baicalin-loaded nanostructured lipid carriers with a particle size of $92 \mathrm{~nm}$, using a high-pressure homogenization method. This nanoformulation not only showed satisfactory physical stability, but also showed higher antidiabetic activity in rats compared to free baicalin [95]. Another approach was adopted to increase the oral bioavailability of baicalin by encapsulating this compound into liposomes. This study revealed that the nanoparticles were highly accumulated in the liver and kidney [96]. Hence, it could be concluded that baicalin-loaded liposomal oral delivery system is an effective nano delivery system which could be employed to deliver drugs to target organs to treat chronic disease such as T2DM.

Another phytobioactive constituent, emodin, which can be found in Chinese herb rhubarb, has been reported to possess a therapeutic effect in T2DM $[97,98]$. However, its low water solubility restricts the clinical uses of the compound. Novel drug delivery approaches have been employed by several workers, which had helped to improve its bioavailability. Ren et al., prepared magnesium silicate hollow nanocarriers with a diameter of around $400 \mathrm{~nm}$ and evaluated their potential to inhibit angiogenesis associated with diabetic retinopathy, which is the main complication of T2DM. The nanoparticles have uniform-sized huge void space and mesoporous shell, allowing them to store high quantities of the drug with sustained-release property. In this in-vitro study, the nanoparticles loaded with emodin could inhibit vascular endothelial growth factor effectively [99]. Nano emodin transferomes with an average particle size of $292.2 \mathrm{~nm}$ and encapsulation efficiency of $69.35 \%$ were developed to deliver emodin through the skin. Transferomes were chosen due to their high skin permeability, which is their ability to penetrate the skin barrier effectively. The findings showed an improved therapeutic effect of the transdermal drug [100]. These nano transfersomes were prepared by Lu et al., using film-ultrasonic dispersion method, followed by the application of the nano transfersome on the abdomen of obese rats. Results showed that the formulation could have a significant anti-obesity effect, which potentially reduces the risk of T2DM [101].

\subsection{Cardioprotective Effect}

Numerous phytoconstituents, especially those that are rich in antioxidant property, have been reported to have a beneficial effect on the cardiovascular system [102]. For example, garlic (Allium sativum) has been known for its anti-cardiovascular properties for decades [103]. It could be used to prevent or treat hyperlipidemia, hypertension, thrombosis and other metabolic diseases. However, garlic oil, the main component of garlic has low solubility in water. A self-nanoemulsifying system containing garlic oil was formulated by Phadatare et al., for improving its oral bioavailability. This for- mulation was filled in hard gelatin capsules for easy swallow purpose, which was designed to disperse to form a nanoemulsion once the capsule comes in contact with the gastric fluid in the stomach. The high surface area of small droplets of nanoemulsion enables the drug to be absorbed effectively and reach blood plasma for circulation [104]. This self-nanoemulsifying system might be a potential drug delivery approach for treating hypertension. Similarly, garlic oil nanoemulsion with a particle size of $24.9 \mathrm{~nm}$ which was synthesized using the ultrasonic emulsification method showed higher efficacy in managing dyslipidemia, the leading risk factor of cardiovascular disease, compared to free garlic oil and atorvastatin. In this in-vivo study, the triglycerides, total cholesterol, low-density lipoprotein cholesterol and very low-density lipoprotein levels in the nanoemulsion-treated Wistar rats significantly reduced and their high-density lipoprotein cholesterol increased in a dose-dependent manner. Other than improved lipid-lowering potential, the nanoemulsion also showed less toxicity than garlic oil with a lethal dose greater than $2.80 \mathrm{ml} / \mathrm{kg}$ [105].

Besides, grapefruit (Citrus paradisi) has been shown to have potent antioxidant, anticoagulant, antithrombotic and antianaemic effects, which is also a potentially useful agent to treat cardiovascular diseases [106,107]. Zinc oxide nanoparticles are being used extensively in industrial sectors dealing with production, due to their unique multifunctional properties. Kumar et al., synthesized zinc oxide nanoparticles by incorporating $C$. paradise peel extract as a stabilizer and further investigated their photocatalytic degradation and antioxidant activity. The findings from the study confirmed that $C$. paradise could fabricate nanoparticles effectively to form a stable nanoformulation, at the same time, the antioxidant effect of the phytoconstituent was also found to be enhanced [108]. The enhanced antioxidant activity of zinc nanoparticles containing $C$. paradise peel extract might have increased the serum antioxidant levels and would have contributed to cardioprotection [109].

The phytoconstituent curcumin that produces the yellow color of turmeric, has demonstrated to have significant cardioprotective effects [110]. A nanocrystalline-chitosan nanocarrier was used by Wang et al., to encapsulate demethoxycurcumin in an attempt to evaluate its inhibitory effect on the migration of vascular smooth muscle cells (VSMCs) that developed in response to arterial injury. This sustained-release nanoformulation with a particle size around $150 \mathrm{~nm}$ inhibited the growth and migration of VSMCs 2.8 times more than free demethoxycurcumin [111]. Later on, Nehra et al., demonstrated that nanocurcumin formulation has a better preventive effect on hypoxia stress in ventricular cardiomyocytes than curcumin. Nanocurcumin reduced the size of hypertrophied cardiomyocytes by $38 \%$ compared to $26 \%$ in curcumin [112]. The same authors then used formulations combined with nanocurcumin

Table 3. Nanocarriers for phytoconstituents used in the management of Type 2 diabetes mellitus.

\begin{tabular}{|c|c|c|c|c|}
\hline $\begin{array}{l}\text { Bioactive com- } \\
\text { pound }\end{array}$ & Nanocarrier & Type of delivery system & $\begin{array}{c}\text { Experimental } \\
\text { model }\end{array}$ & References \\
\hline \multirow[t]{2}{*}{ Berberine } & Solid lipid nanoparticles & Berberine-loaded solid lipid nanoparticles & In-vivo & [87-89] \\
\hline & Lipid-based nanoparticles & Selenium-coated nanostructured lipid carriers & In-vitro/In-vivo & [90] \\
\hline \multirow[t]{3}{*}{ Baicalin } & Nanoemulsion & Internal and external addition of baicalin & In-vitro/In-vivo & [93] \\
\hline & \multirow[t]{2}{*}{ Lipid-based nanoparticles } & Baicalin-loaded nanostructured lipid carriers & In-vitro/In-vivo & [94] \\
\hline & & Baicalin-loaded liposomes & In-vitro/In-vivo & {$[95]$} \\
\hline \multirow[t]{2}{*}{ Emodin } & Silica-based nanoparticles & Emodin-loaded magnesium silicate hollow nanoparticle & In-vitro/Ex-vivo & {$[98]$} \\
\hline & Lipid-based nanoparticles & Emodin-loaded transfersomes & In-vivo & {$[100]$} \\
\hline
\end{tabular}


Table 4. Nanocarriers for cardioprotective phytoconstituents.

\begin{tabular}{|c|c|c|c|c|}
\hline Bioactive compound & Nanocarrier & Type of delivery system & Experimental model & References \\
\hline Grapefruit & Nanoparticles & Grapefruit-loaded zinc oxide nanoparticles & In-vitro & [107] \\
\hline \multirow[t]{2}{*}{ Curcumin } & \multirow[t]{2}{*}{ Nanoparticles } & Nanocrystalline-chitosan nanoparticles & In-vitro & {$[110]$} \\
\hline & & Curcumin-loaded magnetic hydrogel nanocomposite & In-vitro/In-vivo & {$[113]$} \\
\hline Curcumin and lycopene & Nanoemulsion & $\begin{array}{l}\text { Oil-in-water nanoemulsion containing curcumin and } \\
\text { lycopene in oil phase }\end{array}$ & In-vitro & [114] \\
\hline
\end{tabular}

and pyrroloquinoline, a polyphenolic compound found in kiwi fruits, to study their effect against mitochondrial damage. The formulation showed a higher potency in modulating cardiac hypertrophy than nanocurcumin or pyrroloquinoline alone [113]. Recently, an in-vivo study showed magnetic hydrogel nanocomposite loaded with curcumin that was able to show a cardioprotective effect against toxicity induced by doxorubicin. These uniform spherical nanoparticles with a mean diameter of $18-23 \mathrm{~nm}$ and $91 \%$ entrapment efficiency exhibited greater efficacy in reducing cardiac hypertrophy marker ANP, BNP and $\beta$-MHC at mRNA level compared to free curcumin $[114,115]$. Another similar study conducted by Quagliariello et al., evaluated the potential of nanoemulsion loaded with nutraceuticals (lycopene-rich tomato extract and curcumin) against doxorubicin-induced cardiotoxicity. The nanoemulsion demonstrated several molecular mechanisms in protecting the cardiovascular system, including modulation of ATP-dependent mechanisms of $\mathrm{Mg}^{2+}$ uptake and further involved in cellular internalization with actin [115]. Some of the common nanocarriers and the type of delivery system currently used for cardioprotective phytoconstituents are listed in Table 4

\subsection{Hepatoprotective Effect}

There has been a long history of using natural products for treating diseases associated with the liver [114]. Ficus Benjamina is one of the flowering plants that has shown prominent hepatoprotective activity $[6,116]$. Sharma et al., employed a colloidal nanocarrier system to enhance the therapeutic effect of $F$. Benjamina. $\mathrm{He}$ and his team prepared SLNs loaded with the plant extract, with particle sizes that ranged from 20 to $50 \mathrm{~nm}$ and with an encapsulation efficiency range of 68 to $93 \%$. The nanoemulsion was able to restore the serum biomarkers including, ALP, SGOT and SGPT, that were previously altered by simultaneous administration of alcohol and disulfiram [117]. In another study, gold nanoparticles conjugated with garlic showed a significant hepatoprotective effect. The nanoformulation had a urease selective $\mathrm{IC}_{50}$ value of 180.61 $\mathrm{mg} \mathrm{mL}^{-1}$, which was slightly lower than the value for aqueous garlic extract [118].

Another well-known hepatoprotective phytoconstituent, silymarin was incorporated in liquid nanoemulsion by using Shirasu porous glass membrane-emulsification method, and further by using spray-drying technique to convert these into solid nanoparticles for improving the delivery of less water-soluble silymarin to the hepatic tissue. Yang et al., formulated a nanoformulation into dry powder with mean sizes of 214 . nm due to the poor physicochemical and physical stability of the nanoemulsion. In this in-vivo study, the nanoparticles containing silymarin were capable of reducings serum aspartate aminotransferase levels, which were elevated previously by carbon tetrachloride $\left(\mathrm{CCl}_{4}\right)$, while conventional sily- marin powder failed to reduce the elevated serum aspartate aminotransferase levels. Furthermore, the oral bioavailability of nanoparticles was 1.3 times greater than the silymarin powder [119]. Recently, Ahmad et al., developed and optimized stable silymarin nanoemulsion using the aqueous titration method. The nanoemulsion made up of $5.0 \%$ of oil, $28.99 \%$ of a mixture of surfactant and co-surfactant and $65.22 \%$ of water appeared to have the smallest particle size, which was around $21.24 \mathrm{~nm}$. The optimized formulation was further evaluated for its potential activity against hepatocellular carcinoma. The findings revealed that the formulation was able to increase the generation of reactive oxygen species to kill liver carcinoma cells without affecting the healthy cells [120]. In another study, bilisomes loaded with silymarin with an average diameter range from 413 to $686 \mathrm{~nm}$ were prepared using thin-film hydration technique [121]. Bilosomes were used as nanocarriers in this study due to their benefit of bile salts that were contained in the liposomes, which were able to assist in the delivery of the lipophilic drug across the cellular membrane and hence increasing the oral bioavailability of the silymarin [122]. Bilosomes loaded with silymarin have shown the highest hepatoprotective effect and also the highest restoring effect in $\mathrm{CCl}_{4}$ induced liver cell damage compared to free silymarin and marketed silymarin product, Legalon ${ }^{\circledR}$. Silymarin-loaded bilosomes showed a more pronounced effect in reducing alanine aminotransferase and aspartate aminotransferase compared to silymarin-loaded liposomes [121]. Various nanocarriers currently employed for the delivery of hepatoprotective phytoconstituents are summarised in Table 5.

\section{CONCLUSION}

Plant-based bioactive compounds have shown prominent potential in preventing or treating various types of chronic diseases, including type 2 diabetes mellitus, cardiovascular disease, arthritis, hepatic disease and cancer. However, their clinical uses have been limited due to their poor water solubility, low stability in-vivo, low absorption and low bioavailability. Hence, nanocarriers are employed to overcome such barriers to improve solubility and stability of phytoconstituents, to enhance their absorption and reduce their toxicity, which are achieved by reducing their particle sizes and by modifying their surface properties. Nanocarriers have thus provided crucial steps in bringing medicinal phytoconstituents closer to their clinical demand. However, additional studies are required to assess and improve the long-term safety of nanosized phytoconstituents to further enhance their use in biomedicine.

\section{CONSENT FOR PUBLICATION}

Not applicable. 
Table 5. Nanocarriers for hepatoprotective phytoconstituents.

\begin{tabular}{|c|c|c|c|c|}
\hline Bioactive compound & Nanocarrier & Type of delivery system & Experimental model & References \\
\hline \hline Ficus benjamina & Solid lipid nanoparticles & F. benjamina loaded solid lipid nanoparticles & In-vitro/In-vivo & {$[116]$} \\
\hline Garlic & Nanoparticles & Garlic-loaded gold nanoparticles & In-vivo & {$[117]$} \\
\hline \multirow{2}{*}{ Silymarin } & Nanoparticles & Silymarin-loaded solid nanoparticles & In-vivo & {$[118]$} \\
\cline { 2 - 5 } & Nanoemulsion & Silymarin-loaded nanoemulsion & In-vivo & {$[119]$} \\
\cline { 2 - 5 } & Lipid-based nanoparticles & Silymarin-loaded bilosomes & In-vitro/Ex-vivo & {$[121]$} \\
\hline
\end{tabular}

\section{FUNDING}

This research project was supported by a grant from the International Medical University (IMU), Bukit Jalil, Kuala Lumpur, Malaysia [Project ID: BPI-01-2018 (39)]

\section{CONFLICT OF INTEREST}

The authors declare no conflict of interest, financial or otherwise.

\section{ACKNOWLEDGEMENTS}

Declared none.

\section{REFERENCES}

[1] Bawa G, Mahajan R, Mehta M, et al. Herbal drugs for the treatment of opioid withdrawal syndrome: A mini review. Plant Arch 2019; 19: 1055-11.

[2] Khan RA, Aslam M, Ahmed S. Evaluation of Toxicological Profile of a Polyherbal Formulation. Pharmacol Pharm 2016; 7(01): 56-63. http://dx.doi.org/10.4236/pp.2016.71008

[3] Satija S, Mahajan S, Vyas M, et al. Pharmacognostic study of dioscorea villosa leaves. Int J Green Pharm 2018; 12(2): 428.

[4] Kumar P, Mehta M, Satija S, et al. Enzymatic in vitro anti-diabetic activity of few traditional Indian medicinal plants. J Biol Sci 2013; 13: $540-4$.

http://dx.doi.org/10.3923/jbs.2013.540.544

[5] Mehta M, Kalsi V, Sharma N, et al. Pharmacognostic and pharmacological screening of Psidium guajava stem extract for its analgesic potential. Int J Green Pharm 2018; 12: 53-7.

[6] Singh A, Mukhtar HM, Satija S, et al. Development of qualitative pharmacognostic and high-performance thin-layer chromatographic fingerprinting of morphological similar species of genus ficus. Asian J Pharm Clin Res 2018; 11(7): 444.

http://dx.doi.org/10.22159/ajpcr.2018.v11i7.25672

[7] Garg M, Lata K, Satija S. Cytotoxic potential of few Indian fruit peels through 3-(4,5-dimethylthiazol-yl)-2,5-diphenyltetrazolium bromide assay on HepG2 cells. Indian J Pharmacol 2016; 48(1): 648.

http://dx.doi.org/10.4103/0253-7613.174552 PMID: 26997725

[8] Singh H, Satija S, Kaur H, et al. Novel drug delivery approaches for guggul. Plant Arch 2019; 19: 983-93.

[9] Mehta M, Garg M. Proniosomal gel: A promising drug carrier for boswellic acids. J Med Sci 2015; 15: 130-4.

http://dx.doi.org/10.3923/jms.2015.130.134

[10] Mehta M, Dureja H, Garg M. Development and optimization of boswellic acid-loaded proniosomal gel. Drug Deliv 2016; 23(8): 3072-81

http://dx.doi.org/10.3109/10717544.2016.1149744 PMID: 26953869

[11] Wadhwa R, Pandey P, Gupta G, et al. Emerging Complexity and the Need for Advanced Drug Delivery in Targeting Candida Species. Curr Top Med Chem 2019; 19(28): 2593-609.

http://dx.doi.org/10.2174/1568026619666191026105308 PMID: 31746290

[12] Rajeshkumar S, Menon S, Venkat Kumar S, et al. Antibacterial and antioxidant potential of biosynthesized copper nanoparticles medi- ated through Cissus arnotiana plant extract. J Photochem Photobiol B 2019; 197111531

http://dx.doi.org/10.1016/j.jphotobiol.2019.111531

PMID:

31212244

[13] Chellappan DK, Yee NJ, Kaur Ambar Jeet Singh BJ, et al. Formulation and characterization of glibenclamide and quercetin-loaded chitosan nanogels targeting skin permeation. Ther Deliv 2019, 10(5): 281-93.

http://dx.doi.org/10.4155/tde-2019-0019 PMID: 31094299

[14] Din FU, Aman W, Ullah I, et al. Effective use of nanocarriers as drug delivery systems for the treatment of selected tumors. Int J Nanomedicine 2017; 12: 7291-309. http://dx.doi.org/10.2147/IJN.S146315 PMID: 29042776

[15] Singh R, Lillard JW Jr. Nanoparticle-based targeted drug delivery. Exp Mol Pathol 2009; 86(3): 215-23

http://dx.doi.org/10.1016/j.yexmp.2008.12.004 PMID: 19186176

[16] Ng ZY, Wong JY, Panneerselvam J, et al. Assessing the potential of liposomes loaded with curcumin as a therapeutic intervention in asthma. Colloids Surf B Biointerfaces 2018; 172: 51-9. http://dx.doi.org/10.1016/j.colsurfb.2018.08.027 PMID: 30134219

[17] Sharma P, Mehta M, Dhanjal DS, et al. Emerging trends in the novel drug delivery approaches for the treatment of lung cancer. Chem Biol Interact 2019; 309108720

http://dx.doi.org/10.1016/j.cbi.2019.06.033 PMID: 31226287

[18] Dua K, Rapalli VK, Shukla SD, et al. Multi-drug resistant Mycobacterium tuberculosis \& oxidative stress complexity: Emerging need for novel drug delivery approaches. Biomed Pharmacother 2018; 107: 1218-29.

http://dx.doi.org/10.1016/j.biopha.2018.08.101 PMID: 30257336

[19] Mehta M, Deeksha, Sharma N, et al. Interactions with the macrophages: An emerging targeted approach using novel drug delivery systems in respiratory diseases. Chem Biol Interact 2019; 304: 109 http://dx.doi.org/10.1016/j.cbi.2019.02.021 PMID: 30849336

[20] Mehta M, Deeksha, Tewari D, et al. Oligonucleotide therapy: An emerging focus area for drug delivery in chronic inflammatory respiratory diseases. Chem Biol Interact 2019; 308: 206-15. http://dx.doi.org/10.1016/j.cbi.2019.05.028 PMID: 31136735

[21] Oyarzun-Ampuero F, Vidal A, Concha M, Morales J, Orellana S, Moreno-Villoslada I. Nanoparticles for the Treatment of Wounds. Curr Pharm Des 2015; 21(29): 4329-41. http://dx.doi.org/10.2174/1381612821666150901104601 PMID 26323420

[22] Nam G, Rangasamy S, Purushothaman B, et al. The application of bactericidal silver nanoparticles in wound treatment. Nanomater Nanotecho 2015; $5: 23$ http://dx.doi.org/10.5772/60918

[23] Bragg PD, Rainnie DJ. The effect of silver ions on the respiratory chain of Escherichia coli. Can J Microbiol 1974; 20(6): 883-9. http://dx.doi.org/10.1139/m74-135 PMID: 4151872

[24] Bondarenko O, Ivask A, Käkinen A, Kurvet I, Kahru A. Particlecell contact enhances antibacterial activity of silver nanoparticles. PLoS One 2013; 8(5)e64060 http://dx.doi.org/10.1371/journal.pone.0064060 PMID: 23737965

[25] Mukherjee S, Ray S, Thakur RS. Solid lipid nanoparticles: a modern formulation approach in drug delivery system. Indian J Pharm Sci 2009; 71(4): 349-58. http://dx.doi.org/10.4103/0250-474X.57282 PMID: 20502539 
[26] Madan JR, Khude PA, Dua K. Development and evaluation of solid lipid nanoparticles of mometasone furoate for topical delivery. Int $\mathrm{J}$ Pharm Investig 2014; 4(2): 60-4. http://dx.doi.org/10.4103/2230-973X.133047 PMID: 25006550

[27] Arzani G, Haeri A, Daeihamed M, Bakhtiari-Kaboutaraki H, Dadashzadeh S. Niosomal carriers enhance oral bioavailability of carvedilol: effects of bile salt-enriched vesicles and carrier surface charge. Int J Nanomedicine 2015; 10: 4797-813. PMID: 26251598

[28] Dua K, Malyla V, Singhvi G, et al. Increasing complexity and interactions of oxidative stress in chronic respiratory diseases: An emerging need for novel drug delivery systems. Chem Biol Interact 2019; 299: 168-78.

http://dx.doi.org/10.1016/j.cbi.2018.12.009 PMID: 30553721

[29] Madan JR, Ghuge NP, Dua K. Formulation and evaluation of proniosomes containing lornoxicam. Drug Deliv Transl Res 2016; 6(5): 511-8.

http://dx.doi.org/10.1007/s13346-016-0296-9 PMID: 27255375

[30] Patra JK, Das G, Fraceto LF, et al. Nano based drug delivery systems: recent developments and future prospects. J Nanobiotechnology $2018 ; 16(1): 71$

http://dx.doi.org/10.1186/s12951-018-0392-8 PMID: 30231877

[31] Mehta M, Satija S, Nanda A, et al. Nanotechnologies for Boswellic Acids. Amer J Drug Dis Dev 2014; 4: 1-11.

[32] Chellappan DK, Ng ZY, Wong JY, et al. Immunological axis of curcumin-loaded vesicular drug delivery systems. Future Med Chem 2018; 10(8): 839-44.

http://dx.doi.org/10.4155/fmc-2017-0245 PMID: 29620416

[33] Aljabali AAA, Bakshi HA, Hakkim FL, et al. Albumin nanoencapsulation of piceatannol enhances its anticancer potential in colon cancer via downregulation of nuclear p65 and HIF-1 $\alpha$. Cancers (Basel) 2020; 12(1)E113

http://dx.doi.org/10.3390/cancers12010113 PMID: 31906321

[34] Gelperina S, Kisich K, Iseman MD, Heifets L. The potential advantages of nanoparticle drug delivery systems in chemotherapy of tuberculosis. Am J Respir Crit Care Med 2005; 172(12): 1487-90. http://dx.doi.org/10.1164/rccm.200504-613PP PMID: 16151040

[35] Hinge N, Pandey MM, Singhvi G, et al. Nanomedicine advances in cancer therapy.Advanced 3D-Printed Systems and Nanosystems for Drug Delivery and Tissue Engineering Woodhead Publishing Series in Biomaterials. Elsevier 2020; pp. 219-53. http://dx.doi.org/10.1016/B978-0-12-818471-4.00008-X

[36] De Jong WH, Borm PJA. Drug delivery and nanoparticles:applications and hazards. Int J Nanomedicine 2008; 3(2): 13349.

http://dx.doi.org/10.2147/IJN.S596 PMID: 18686775

[37] Nanotechnologies [homepage on the Internet]. n.d. [cited $2020 \mathrm{Mar}$ 30] Available from: https:/ec.europa.eu/health/scientific_committees/opinions_laym an/en/nanotechnologies/

[38] Awasthi R, Roseblade A, Hansbro PM, Rathbone MJ, Dua K, Bebawy M. Nanoparticles in Cancer Treatment: Opportunities and Obstacles. Curr Drug Targets 2018; 19(14): 1696-709.

http://dx.doi.org/10.2174/1389450119666180326122831 PMID: 29577855

[39] Jeevanandam J, Chan YS, Danquah MK. Nano-formulations of drugs: Recent developments, impact and challenges. Biochimie 2016; 128-129: 99-112. http://dx.doi.org/10.1016/j.biochi.2016.07.008 PMID: 27436182

[40] Brohi RD, Wang L, Talpur HS, et al. Toxicity of nanoparticles on the reproductive system in animal models: A review. Front Pharmacol 2017; 8: 606 .

http://dx.doi.org/10.3389/fphar.2017.00606 PMID: 28928662

[41] Khalili Fard J, Jafari S, Eghbal MA. A review of molecular mechanisms involved in toxicity of nanoparticles. Adv Pharm Bull 2015; 5(4): 447-54.

http://dx.doi.org/10.15171/apb.2015.061 PMID: 26819915

[42] Bahadar H, Maqbool F, Niaz K, Abdollahi M. Toxicity of nanoparticles and an overview of current experimental models. Iran Biomed J 2016; 20(1): 1-11.

PMID: 26286636

[43] Gupta P, Gupta A, Agarwal K, Tomar P, Satija S. Antioxidant and cytotoxic potential of a new thienyl derivative from Tagetes erecta roots. Pharm Biol 2012; 50(8): 1013-8. http://dx.doi.org/10.3109/13880209.2012.655378 PMID: 22775418

[44] Roy NK, Parama D, Banik K, et al. An update on pharmacological potential of boswellic acids against chronic diseases. Int J Mol Sci 2019; 20(17)E4101

http://dx.doi.org/10.3390/ijms20174101 PMID: 31443458

[45] Aggarwal BB, Kumar A, Bharti AC. Anticancer potential of curcumin: preclinical and clinical studies. Anticancer Res 2003; 23(1A): 363-98.

PMID: 12680238

[46] Smith GA. Current status of vinorelbine for breast cancer. Oncology (Williston Park) 1995; 9(8): 767-73.

PMID: 7577376

[47] Singh S, Sharma B, Kanwar SS, Kumar A. Lead phytochemicals for anticancer drug development. Front Plant Sci 2016; 7: 1667. http://dx.doi.org/10.3389/fpls.2016.01667 PMID: 27877185

[48] Kaur R, Satija S, Kalsi V, et al. Comparative study of analgesic and antipyretic activity of curcuma caesia and curcuma amada roxb. rhizomes. Inventi Imp Ethnopharmacol 2011; 3: 441-3.

[49] Kunnumakkara AB, Guha S, Krishnan S, Diagaradjane P, Gelovani J, Aggarwal BB. Curcumin potentiates antitumor activity of gemcitabine in an orthotopic model of pancreatic cancer through suppression of proliferation, angiogenesis, and inhibition of nuclear factor-kappaB-regulated gene products. Cancer Res 2007; 67(8): 3853-61.

http://dx.doi.org/10.1158/0008-5472.CAN-06-4257

PMID: 17440100

[50] Collett GP, Campbell FC. Curcumin induces c-jun N-terminal kinase-dependent apoptosis in HCT116 human colon cancer cells. Carcinogenesis 2004; 25(11): 2183-9.

http://dx.doi.org/10.1093/carcin/bgh233 PMID: 15256484

[51] Rahmani AH, Al Zohairy MA, Aly SM, Khan MA. Curcumin: a potential candidate in prevention of cancer via modulation of molecular pathways. BioMed Res Int 2014; 2014761608 http://dx.doi.org/10.1155/2014/761608 PMID: 25295272

[52] Kamat AM, Sethi G, Aggarwal BB. Curcumin potentiates the apoptotic effects of chemotherapeutic agents and cytokines through down-regulation of nuclear factor-kappaB and nuclear factorkappaB-regulated gene products in IFN- $\alpha$-sensitive and IFN- $\alpha$ resistant human bladder cancer cells. Mol Cancer Ther 2007; 6(3): 1022-30.

http://dx.doi.org/10.1158/1535-7163.MCT-06-0545

PMID: 17363495

[53] Zaman MS, Chauhan N, Yallapu MM, et al. Curcumin Nanoformulation for Cervical Cancer Treatment. Sci Rep 2016; 6: 20051 http://dx.doi.org/10.1038/srep20051 PMID: 26837852

[54] Yallapu MM, Gupta BK, Jaggi M, Chauhan SC. Fabrication of curcumin encapsulated PLGA nanoparticles for improved therapeutic effects in metastatic cancer cells. J Colloid Interface Sci 2010; 351(1): 19-29.

http://dx.doi.org/10.1016/j.jcis.2010.05.022 PMID: 20627257

[55] Ndong Ntoutoume GMA, Granet R, Mbakidi JP, et al. Development of curcumin-cyclodextrin/cellulose nanocrystals complexes: New anticancer drug delivery systems. Bioorg Med Chem Lett 2016; 26(3): 941-5 http://dx.doi.org/10.1016/j.bmcl.2015.12.060 PMID: 26739777

[56] Ahmadi Nasab N, Hassani Kumleh H, Beygzadeh M, Teimourian S, Kazemzad M. Delivery of curcumin by a $\mathrm{pH}$-responsive chitosan mesoporous silica nanoparticles for cancer treatment. Artif Cells Nanomed Biotechnol 2018; 46(1): 75-81.

http://dx.doi.org/10.1080/21691401.2017.1290648

PMID: 28278578

[57] Landen JW, Lang R, McMahon SJ, et al. Noscapine alters microtubule dynamics in living cells and inhibits the progression of melanoma. Cancer Res 2002; 62(14): 4109-14.

PMID: 12124349

[58] Madan J, Pandey RS, Jain V, Katare OP, Chandra R, Katyal A. Poly (ethylene)-glycol conjugated solid lipid nanoparticles of noscapine improve biological half-life, brain delivery and efficacy in glioblastoma cells. Nanomedicine (Lond) 2013; 9(4): 492-503. http://dx.doi.org/10.1016/j.nano.2012.10.003 PMID: 23117045

[59] Zhou J, Gupta K, Aggarwal S, et al. Brominated derivatives of noscapine are potent microtubule-interfering agents that perturb mitosis and inhibit cell proliferation. Mol Pharmacol 2003; 63(4): 799807. 
http://dx.doi.org/10.1124/mol.63.4.799 PMID: 12644580

[60] Jyoti K, Kaur K, Pandey RS, Jain UK, Chandra R, Madan J. Inhalable nanostructured lipid particles of 9-bromo-noscapine, a tubulin-binding cytotoxic agent: in vitro and in vivo studies. J Colloid Interface Sci 2015; 445: 219-30.

http://dx.doi.org/10.1016/j.jcis.2014.12.092 PMID: 25622047

[61] Kuo HP, Hsu SC, Ou CC, et al. Ganoderma tsugae extract inhibits growth of her2-overexpressing cancer cells via modulation of HER2/PI3K/Akt signaling pathway. Evid Based Complement Alternat Med 2013; 2013219472

http://dx.doi.org/10.1155/2013/219472 PMID: 23662119

[62] Maurya H, Dhiman S, Dua K, Gupta G. Pharmacological effect of berberine chloride in propyl thiouracil induced thyroidal dysfunction - a time bound study in female rats. Recent Pat Drug Deliv Formul 2016; 10(2): 165-73.

http://dx.doi.org/10.2174/1872211310666160321123610 PMID: 26996367

[63] Singh H, Mehta M, Khurana N, et al. Recent patent technologies of tinospora cordifolia for anti-diabetic potential: A review. Plant Arch 2019; 19: 994-9.

[64] Tew XN, Xin Lau NJ, Chellappan DK, et al. Immunological axis of berberine in managing inflammation underlying chronic respiratory inflammatory diseases. Chem Biol Interact 2020; 317108947 http://dx.doi.org/10.1016/j.cbi.2020.108947 PMID: 31968208

[65] Bhanumathi R, Vimala K, Shanthi K, et al. Bioformulation of silver nanoparticles as berberine carrier cum anticancer agent against breast cancer. New J Chem 2017; 41(23): 14466-77. http://dx.doi.org/10.1039/C7NJ02531A

[66] Wang L, Li H, Wang S, et al. Enhancing the antitumor activity of berberine hydrochloride by solid lipid nanoparticle encapsulation. AAPS PharmSciTech 2014; 15(4): 834-44. http://dx.doi.org/10.1208/s12249-014-0112-0 PMID: 24696391

[67] Gupta L, Sharma AK, Gothwal A, et al. Dendrimer encapsulated and conjugated delivery of berberine: A novel approach mitigating toxicity and improving in vivo pharmacokinetics. Int J Pharm 2017; 528(1-2): 88-99.

http://dx.doi.org/10.1016/j.ijpharm.2017.04.073 PMID: 28533175

[68] Li L, Li X, Huang X, et al. Synergistic anticancer effects of nanocarrier loaded with berberine and miR-122. Biosci Rep 2018; 38(3)BSR20180311

http://dx.doi.org/10.1042/BSR20180311 PMID: 29769413

[69] Mancarella S, Greco V, Baldassarre F, Vergara D, Maffia M, Leporatti S. Polymer-Coated Magnetic Nanoparticles for Curcumin Delivery to Cancer Cells. Macromol Biosci 2015; 15(10): 1365-74. http://dx.doi.org/10.1002/mabi.201500142 PMID: 26085082

[70] Hughes SD, Ketheesan N, Haleagrahara N. The therapeutic potential of plant flavonoids on rheumatoid arthritis. Crit Rev Food Sci Nutr 2017; 57(17): 3601-13.

http://dx.doi.org/10.1080/10408398.2016.1246413 PMID: 27874281

[71] Guardia T, Rotelli AE, Juarez AO, Pelzer LE. Anti-inflammatory properties of plant flavonoids. Effects of rutin, quercetin and hesperidin on adjuvant arthritis in rat. Farmaco 2001; 56(9): 683-7. http://dx.doi.org/10.1016/S0014-827X(01)01111-9 PMID: 11680812

[72] Ji JJ, Lin Y, Huang SS, Zhang HL, Diao YP, Li K. Quercetin: a potential natural drug for adjuvant treatment of rheumatoid arthritis. Afr J Tradit Complement Altern Med 2013; 10(3): 418-21. PMID: 24146468

[73] Jeyadevi R, Sivasudha T, Rameshkumar A, et al. Enhancement of anti arthritic effect of quercetin using thioglycolic acid-capped cadmium telluride quantum dots as nanocarrier in adjuvant induced arthritic Wistar rats. Colloids Surf B Biointerfaces 2013; 112: 25563

http://dx.doi.org/10.1016/j.colsurfb.2013.07.065 PMID: 23994749

[74] Sarwa KK, Mazumder B, Rudrapal M, Verma VK. Potential of capsaicin-loaded transfersomes in arthritic rats. Drug Deliv 2015; 22(5): 638-46.

http://dx.doi.org/10.3109/10717544.2013.871601 PMID: 24471764

[75] Kumar Sarwa K, Rudrapal M, Mazumder B. Topical ethosomal capsaicin attenuates edema and nociception in arthritic rats. Drug Deliv 2015; 22(8): 1043-52.

http://dx.doi.org/10.3109/10717544.2013.861041 PMID: 24506573
[76] Garg C, Thakur S, Satija SM, et al. Stability indicating HPTLC studies of piperine through method development and analysis. Int $\mathbf{J}$ Pharm Sci Res 2016; 1(7): 24-9.

[77] Bhalekar MR, Madgulkar AR, Desale PS, Marium G. Formulation of piperine solid lipid nanoparticles (SLN) for treatment of rheumatoid arthritis. Drug Dev Ind Pharm 2017; 43(6): 1003-10. http://dx.doi.org/10.1080/03639045.2017.1291666

PMID: 28161984

[78] Bhalekar MR, Madgulkar AR, Aswar M, et al. A Comparative Study of Oral and Topical Administration of Hesperidin Lipid Nanoparticles in Rheumatoid Arthritis. Austin Arthritis 2016; 1(2): 1010 .

[79] Rao K, Aziz S, Roome T, et al. Gum acacia stabilized silver nanoparticles based nano-cargo for enhanced anti-arthritic potentials of hesperidin in adjuvant induced arthritic rats. Artif Cells Nanomed Biotechnol 2018; 46(sup1): 597-607. http://dx.doi.org/10.1080/21691401.2018.1431653

[80] McInnes IB, Schett G. The pathogenesis of rheumatoid arthritis. N Engl J Med 2011; 365(23): 2205-19.

http://dx.doi.org/10.1056/NEJMra1004965 PMID: 22150039

[81] Zheng Z, Sun Y, Liu Z, Zhang M, Li C, Cai H. The effect of curcumin and its nanoformulation on adjuvant-induced arthritis in rats. Drug Des Devel Ther 2015; 9: 4931-42.

PMID: 26345159

[82] Zhang Z, Leong DJ, Xu L, et al. Curcumin slows osteoarthritis progression and relieves osteoarthritis-associated pain symptoms in a post-traumatic osteoarthritis mouse model. Arthritis Res Ther 2016; 18(1): 128 http://dx.doi.org/10.1186/s13075-016-1025-y PMID: 27260322

[83] Niazvand F, Khorsandi L, Abbaspour M, et al. Curcumin-loaded poly lactic-co-glycolic acid nanoparticles effects on monoiodoacetate -induced osteoarthritis in rats. Vet Res Forum 2017; $8(2): 155-61$

PMID: 28785392

[84] Gupta G, Wadhwa R, Pandey P, et al. Obesity and Diabetes: Pathophysiology of obesity-induced hyperglycemia and insulin resistance. In: Pathophysiology of Obesity-Induced Health Complications . Springer International Publishing 2020; p. 81-97.

[85] Ganesan P, Arulselvan P, Choi DK. Phytobioactive compoundbased nanodelivery systems for the treatment of type 2 diabetes mellitus - current status. Int J Nanomedicine 2017; 12: 1097-111. http://dx.doi.org/10.2147/IJN.S124601 PMID: 28223801

[86] Usman B, Sharma N, Satija S, et al. Recent Developments in Alpha-Glucosidase Inhibitors for Management of Type-2 Diabetes: An Update. Curr Pharm Des 2019; 25(23): 2510-25. http://dx.doi.org/10.2174/1381612825666190717104547 PMID 31333110

[87] Zhang M, Chen L. Berberine in type 2 diabetes therapy: a new perspective for an old antidiarrheal drug? Acta Pharm Sin B 2012; 2(4): 379-86.

http://dx.doi.org/10.1016/j.apsb.2012.06.004 PMID: 23710432

[88] Xue M, Yang MX, Zhang W, et al. Characterization, pharmacokinetics, and hypoglycemic effect of berberine loaded solid lipid nanoparticles. Int J Nanomedicine 2013; 8: 4677-87. http://dx.doi.org/10.2147/IJN.S51262 PMID: 24353417

[89] Xue M, Zhang L, Yang MX, et al. Berberine-loaded solid lipid nanoparticles are concentrated in the liver and ameliorate hepatosteatosis in $\mathrm{db} / \mathrm{db}$ mice. Int J Nanomedicine 2015; 10: 5049-57. http://dx.doi.org/10.2147/IJN.S84565 PMID: 26346310

[90] Wang Z, Wu J, Zhou Q, Wang Y, Chen T. Berberine nanosuspension enhances hypoglycemic efficacy on streptozotocin induced diabetic C57BL/6 mice. Evid Based Complement Alternat Med $2015 ; 2015239749$ http://dx.doi.org/10.1155/2015/239749 PMID: 25866534

[91] Andrade LM, de Fátima Reis C, Maione-Silva L, et al. Impact of lipid dynamic behavior on physical stability, in vitro release and skin permeation of genistein-loaded lipid nanoparticles. Eur J Pharm Biopharm 2014; 88(1): 40-7. http://dx.doi.org/10.1016/j.ejpb.2014.04.015 PMID: 24816130

[92] Yin J, Hou Y, Yin Y, Song X. Selenium-coated nanostructured lipid carriers used for oral delivery of berberine to accomplish a synergic hypoglycemic effect. Int J Nanomedicine 2017; 12: 8671-80. http://dx.doi.org/10.2147/IJN.S144615 PMID: 29263662 
[93] Li B, Wen M, Li W, He M, Yang X, Li S. Preparation and characterization of baicalin-poly -vinylpyrrolidone coprecipitate. Int $\mathrm{J}$ Pharm 2011; 408(1-2): 91-6. http://dx.doi.org/10.1016/j.ijpharm.2011.01.055 PMID: 21291971

[94] Zhao L, Wei Y, Huang Y, He B, Zhou Y, Fu J. Nanoemulsion improves the oral bioavailability of baicalin in rats: in vitro and in vivo evaluation. Int J Nanomedicine 2013; 8: 3769-79.

http://dx.doi.org/10.2147/IJN.S51578 PMID: 24124365

[95] Shi F, Wei Z, Zhao Y, Xu X. Nanostructured lipid carriers loaded with Baicalin: An efficient carrier for enhanced antidiabetic effects. Pharmacogn Mag 2016; 12(47): 198-202.

http://dx.doi.org/10.4103/0973-1296.186347 PMID: 27601850

[96] Wei Y, Guo J, Zheng X, et al. Preparation, pharmacokinetics and biodistribution of baicalin-loaded liposomes. Int $\mathrm{J}$ Nanomedicine 2014; 9: 3623-30.

PMID: 25120360

[97] Song P, Kim JH, Ghim J, et al. Emodin regulates glucose utilization by activating AMP-activated protein kinase. J Biol Chem 2013; 288(8): 5732-42.

http://dx.doi.org/10.1074/jbc.M112.441477 PMID: 23303186

[98] Song Y, Fan X, Guo Z, et al. Therapeutic effects of emodin in type 2 diabetes mellitus in KKAy mouse model. Int J Clin Exp Med 2017; 10(10): 14408-13.

[99] Ren H, Zhu C, Li Z, Yang W, Song E. Emodin-loaded magnesium silicate hollow nanocarriers for anti-angiogenesis treatment through inhibiting VEGF. Int J Mol Sci 2014; 15(9): 16936-48.

http://dx.doi.org/10.3390/ijms150916936 PMID: 25250911

[100] Rajan R, Jose S, Mukund VP, Vasudevan DT. Transferosomes - A vesicular transdermal delivery system for enhanced drug permeation. J Adv Pharm Technol Res 2011; 2(3): 138-43.

http://dx.doi.org/10.4103/2231-4040.85524 PMID: 22171309

[101] Lu K, Xie S, Han S, et al. Preparation of a nano emodin transfersome and study on its anti-obesity mechanism in adipose tissue of diet-induced obese rats. J Transl Med 2014; 12: 72.

http://dx.doi.org/10.1186/1479-5876-12-72 PMID: 24641917

[102] Pagliaro B, Santolamazza C, Simonelli F, Rubattu S. Phytochemical compounds and protection from cardiovascular diseases: a state of the art. BioMed Res Int 2015; 2015918069

http://dx.doi.org/10.1155/2015/918069 PMID: 26504846

[103] Nwokocha CR, Ozolua RI, Owu DU, Nwokocha MI, Ugwu AC. Antihypertensive properties of Allium sativum (garlic) on normotensive and two kidney one clip hypertensive rats. Niger J Physiol Sci 2011; 26(2): 213-8. PMID: 22547193

[104] Phadatare AG, Viswanathan V, Mukne A. Novel strategies for optimized delivery of select components of Allium sativum. Pharmacognosy Res 2014; 6(4): 334-40.

http://dx.doi.org/10.4103/0974-8490.138288 PMID: 25276072

[105] Ragavan G, Muralidaran Y, Sridharan B, Nachiappa Ganesh R, Viswanathan P. Evaluation of garlic oil in nano-emulsified form: Optimization and its efficacy in high-fat diet induced dyslipidemia in Wistar rats. Food Chem Toxicol 2017; 105: 203-13. http://dx.doi.org/10.1016/j.fct.2017.04.019 PMID: 28428086

[106] Onakpoya I, O'Sullivan J, Heneghan C, Thompson M. The effect of grapefruits (Citrus paradisi) on body weight and cardiovascular risk factors: A systematic review and meta-analysis of randomized clinical trials. Crit Rev Food Sci Nutr 2017; 57(3): 602-12.

http://dx.doi.org/10.1080/10408398.2014.901292 PMID: 25880021

[107] Riaz A, Khan RA. Anticoagulant, antiplatelet and antianemic effects of Punica granatum (pomegranate) juice in rabbits. Blood Coagul Fibrinolysis 2016; 27(3): 287-93.

http://dx.doi.org/10.1097/MBC.0000000000000415 PMID: 26881853

[108] Kumar B, Smita K, Cumbal L, Debut A. Green approach for fabrication and applications of zinc oxide nanoparticles. Bioinorg Chem Appl 2014; 2014523869

http://dx.doi.org/10.1155/2014/523869 PMID: 25374484
[109] Hamilton KL. Antioxidants and cardioprotection. Med Sci Sports Exerc 2007; 39(9): 1544-53.

http://dx.doi.org/10.1249/mss.0b013e3180d099e8 PMID: 17805087

[110] Miriyala S, Panchatcharam M, Rengarajulu P. Cardioprotective effects of curcumin. Adv Exp Med Biol 2007; 595: 359-77. http://dx.doi.org/10.1007/978-0-387-46401-5 16 PMID: 17569220

[111] Wang YJ, Lin HY, Wu CH, Liu DM. Forming of demethoxycurcumin nanocrystallite-chitosan nanocarrier for controlled low dose cellular release for inhibition of the migration of vascular smooth muscle cells. Mol Pharm 2012; 9(8): 2268-79.

http://dx.doi.org/10.1021/mp300150q PMID: 22788791

[112] Nehra S, Bhardwaj V, Ganju L, Saraswat D. Nanocurcumin prevents hypoxia induced stress in primary human ventricular cardiomyocytes by maintaining mitochondrial homeostasis. PLoS One 2015; 10(9)e 0139121

http://dx.doi.org/10.1371/journal.pone.0139121 PMID: 26406246

[113] Nehra S, Bhardwaj V, Bansal A, Chattopadhyay P, Saraswat D. Nanocurcumin-pyrroloquinoline formulation prevents hypertrophyinduced pathological damage by relieving mitochondrial stress in cardiomyocytes under hypoxic conditions. Exp Mol Med 2017; 49(12)e404

http://dx.doi.org/10.1038/emm.2017.199 PMID: 29611541

[114] Namdari M, Eatemadi A. Cardioprotective effects of curcuminloaded magnetic hydrogel nanocomposite (nanocurcumin) against doxorubicin-induced cardiac toxicity in rat cardiomyocyte cell lines. Artif Cells Nanomed Biotechnol 2017; 45(4): 731-9.

http://dx.doi.org/10.1080/21691401.2016.1261033

PMID: 27924631

[115] Quagliariello V, Vecchione R, Coppola C, et al. Cardioprotective effects of nanoemulsions loaded with anti-inflammatory nutraceuticals against doxorubicin-induced cardiotoxicity. Nutrients 2018; 10(9)E1304

http://dx.doi.org/10.3390/nu10091304 PMID: 30223482

[116] Kalaskar MG, Surana SJ. Free radical scavenging and hepatoprotective potential of Ficus microcarpa L. fil. bark extracts. J Nat Med 2011; 65(3-4): 633-40.

http://dx.doi.org/10.1007/s1 1418-011-0532-z PMID: 21625948

[117] Sharma AK, Kumar A, Kumar S, et al. Preparation and therapeutic evolution of Ficus benjamina solid lipid nanoparticles against alcohol abuse/antabuse induced hepatotoxicity and cardio-renal injury. RSC Advances 2017; 7: 35938-49. http://dx.doi.org/10.1039/C7RA04866A

[118] Ateeq M, Shah MR, Ali H, et al. Hepatoprotective and urease inhibitory activities of garlic conjugated gold nanoparticles. New J Chem 2015; 39: 5003-7. http://dx.doi.org/10.1039/C5NJ00030K

[119] Yang KY, Hwang H, Yousaf AM, et al. Silymarin-loaded solid nanoparticles provide excellent hepatic protection: physicochemical characterization and in vivo evaluation. Int $\mathbf{J}$ Nanomedicine 2013; 8: 3333-43. PMID: 24039417

[120] Ahmad U, Akhtar J, Singh SP, Ahmad FJ, Siddiqui S. Silymarin nanoemulsion against human hepatocellular carcinoma: development and optimization. Artif Cells Nanomed Biotechnol 2018; 46(2): 231-41.

http://dx.doi.org/10.1080/21691401.2017.1324465

PMID: 28503949

[121] Mohsen AM, Asfour MH, Salama AAA. Improved hepatoprotective activity of silymarin via encapsulation in the novel vesicular nanosystem bilosomes. Drug Dev Ind Pharm 2017; 43(12): 204354.

http://dx.doi.org/10.1080/03639045.2017.1361968

PMID: 28756693

[122] Mikov M, Fawcett JP, Kuhajda K, Kevresan S. Pharmacology of bile acids and their derivatives: absorption promoters and therapeutic agents. Eur J Drug Metab Pharmacokinet 2006; 31(3): 237-51. http://dx.doi.org/10.1007/BF03190714 PMID: 17136862 